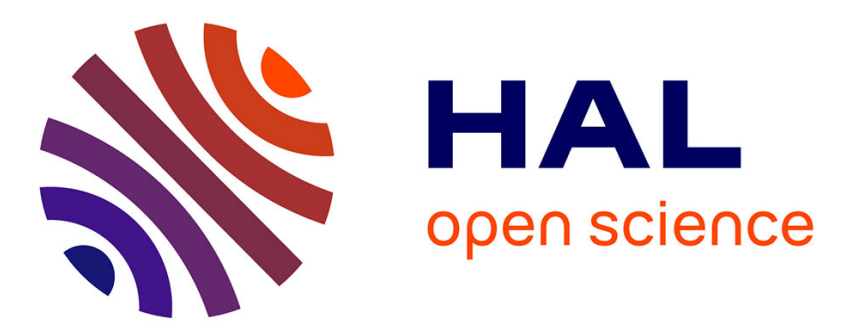

\title{
The Seè Method For Determination Of Behaviour Laws For Strain Rate Dependent Material: Application To Polymer Material
}

\author{
Franck Lauro, Bruno Bennani, D. Morin, A. F Epee
}

\section{To cite this version:}

Franck Lauro, Bruno Bennani, D. Morin, A. F Epee. The Seè Method For Determination Of Behaviour Laws For Strain Rate Dependent Material: Application To Polymer Material. International Journal of Impact Engineering, 2010, 37 (6), pp.715. 10.1016/j.ijimpeng.2009.11.007 . hal-00674107

\section{HAL Id: hal-00674107 https://hal.science/hal-00674107}

Submitted on 25 Feb 2012

HAL is a multi-disciplinary open access archive for the deposit and dissemination of scientific research documents, whether they are published or not. The documents may come from teaching and research institutions in France or abroad, or from public or private research centers.
L'archive ouverte pluridisciplinaire HAL, est destinée au dépôt et à la diffusion de documents scientifiques de niveau recherche, publiés ou non, émanant des établissements d'enseignement et de recherche français ou étrangers, des laboratoires publics ou privés. 


\section{Accepted Manuscript}

Title: The Seè Method For Determination Of Behaviour Laws For Strain Rate

Dependent Material: Application To Polymer Material

Authors: F. Lauro., B. Bennani, D. Morin, A. F Epee

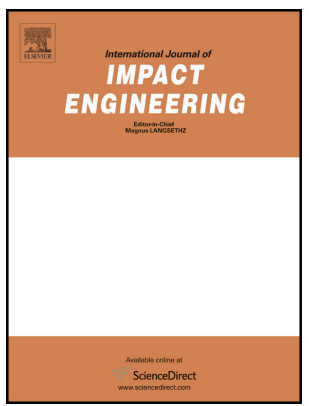

PII:

S0734-743X(09)00209-7

DOI:

10.1016/j.ijimpeng.2009.11.007

Reference: IE 1855

To appear in: International Journal of Impact Engineering

Received Date: 28 November 2008

Revised Date: 11November2009

Accepted Date: 13 November 2009

Please cite this article as: Lauro. F, Bennani B, Morin D, Epee AF. The See Method For Determination Of Behaviour Laws For Strain Rate Dependent Material: Application To Polymer Material, International Journal of Impact Engineering (2009), doi: 10.1016/j.ijimpeng.2009.11.007

This is a PDF file of an unedited manuscript that has been accepted for publication. As a service to our customers we are providing this early version of the manuscript. The manuscript will undergo copyediting, typesetting, and review of the resulting proof before it is published in its final form. Please note that during the production process errors may be discovered which could affect the content, and all legal disclaimers that apply to the journal pertain. 
THE SEE METHOD FOR DETERMINATION OF BEHAVIOUR LAWS FOR STRAIN RATE DEPENDENT MATERIAL: APPLICATION TO POLYMER MATERIAL.

LAURO F., BENNANI B., MORIN D., EPEE A. F., Laboratory of Industrial and Human Automation Control, Mechanical Engineering and Computer Sciences, LAMIH - UMR CNRS 8530, University of Valenciennes, Le Mont Houy, 59313 Valenciennes Cedex 9, France.

Email:franck.lauro@univ-valenciennes.fr

\section{Abstract:}

The need to model fracture in crashworthiness by means of finite element codes is a real challenge for research. Before implementing fracture criteria, an excellent knowledge of the stress and strain states in the material just before the crack appearance is the first condition necessary to ensure the model development. At present, most of the material behaviour laws, for example for steel, are only defined until the maximum force when necking occurs. For polymers, the early occurrence of the diffuse necking leads to an experimental technique in which the speed loading is controlled in real time to maintain a constant strain rate during the test. This technique is not however used, due to technical limitations, for high strain rate behaviour laws. In this paper, the authors propose to use the heterogeneity of the displacement field on the surface of the tensile specimen as an initial condition to identify behaviour laws. The method developed uses the information in all the surface zone of the specimen by using digital image correlation. Stresses, strains and strain rates are then obtained to build a surface behaviour called the SEE surface. By cutting it, the experimental behaviour laws for a range of large strains and strain rates are then defined for model identification.

Keywords: behaviour law, image correlation, strain rate, polymer.

Symbols:

$\Delta F^{\prime}: \quad$ Force increment

F: $\quad$ Force

f, g: Displacement functions

$\Delta S: \quad$ Section variation 
$\mathrm{S}_{0}: \quad$ Initial section

$\overline{\mathrm{u}}$ : $\quad$ Displacement field

$\overline{\mathrm{x}}$ : Position

$\sigma: \quad$ True stress

$\sigma_{\mathrm{ii}}: \quad$ Stress in direction $\mathrm{i}$

$\varepsilon: \quad$ Total strain tensor

$\varepsilon_{\mathrm{ii}}$ : $\quad$ Strain in direction $\mathrm{i}$

$\varepsilon_{\mathrm{ii}}: \quad$ Strain rate in direction $\mathrm{i}$

At: $\quad$ Time increment

\section{Introduction}

Polymers are increasingly being used in the field of transportation (automotive, aeronautics

...). Car manufacturers in particular appreciate the lightness of these materials with respect to the European norm of 2008. In the past, they were mainly used inside the car but, over the last fifteen years, polymers have also been used for structural parts of cars like bumpers, wings, etc.... In addition, some safety norms, especially for pedestrian impacts or driver/passenger safety, have led car manufacturers to study the behaviour of polymers in more detail in the case of multiaxial loading for a wide range of plastic strain rates and temperatures.

Unfortunately, polymers are known to be sensitive to both strain rates and loading conditions. Moreover, the early presence of necking leads to a non uniform plastic strain field on a classical tensile test specimen. Consequently, the determination of the uniaxial true stressstrain curve is really difficult to perform. This problematic is increased in the case of a specimen with a rectangular cross-section for which the classical hypothesis of Bridgman can't be applied [1].

Nevertheless, the determination of the true stress-strain curve becomes essential when large plastic deformations and large plastic strain rates are considered, in particular to perform ductile damage or fracture analysis. The first difficulty of this determination is the heterogeneity of the plastic strain field and the stress field in the cross-section of the specimen after the occurrence of necking. In this case, the stress could be determined by 
$\sigma=\lim _{\Delta \rightarrow \infty}\left(\frac{\Delta F}{\Delta S}\right)$ where $\Delta \mathrm{F}$ is the force increment on the tensile specimen and $\Delta \mathrm{S}$ the section variation associated to it. Until now, these values have been difficult to obtain during a tensile test and this has led to the calculation of an average stress. To improve results, Bridgman [1] uses a correction technique which takes the radial and hoop stresses into account in the calculation of the nominal stress for a round bar specimen. This technique is difficult to extend to rectangular cross-section specimens because of the stress state which cannot be calculated easily with a non axisymetric specimen. Consequently, Ling et al.[2] proposes a weighted-average method for determining uniaxial true tensile stress versus strain relation after necking for strip shaped samples. The true stress-strain function after the onset of necking is corrected by the weighted average function which is determined by using lower and upper bounds of the true stress-strain curves. The parameters of this function are identified by means of an optimisation process which correlates the force displacement curves obtained by the simulation of a tensile test and an experimental one. This technique is also used for damage models identification [3] but the solution depends on both the optimisation algorithm and the amount of experimental data.

Based on the same approach as Bridgman, Zhang et al.[4] proposes an extensive three dimensional numerical study on the diffuse necking with tensile specimen with a rectangular cross-section. An approximate relation is established between the area reduction of the minimum cross-section and the measured thickness reduction. A method is then proposed to determine the true stress-logarithmic strain relation from the load thickness reduction curve. This technique is also extended to anisotropic material by observing the width reduction of the tensile specimen in addition [5]. A technique is developed by G'sell et al.[6] for the purpose of polymer materials. An experimental set up dedicated to the analysis of the displacement fields on a tensile test is built to take the volume variation into account. The damage process in polymer material is so important that it modifies the volume of the tensile 
specimen and in this way the total strain. This cannot be introduced in the correction technique based on the Bridgman hypothesis. G'sell then uses a specific experimental technique coupled with the calculation of the plastic strain in the three principal directions. The displacement in the direction of the tension is used to control the speed of the machine in real time. For that, a tensile test with a seven spots specimen is carried out and the spots displacements are followed by a camera. (Fig.1)

The axial strain is then calculated with a Lagrangian formalism between each spot in the axis $\mathrm{AE}$ and interpolated by a polynomial equation along the entire specimen in order to become the true strain. The transverse strain is calculated using the same approach with the spots placed on the horizontal axis FG. Finally, the strain in the thickness is obtained by an incompressible or transverse isotropic hypothesis. The true stress can then be calculated with using the same hypothesis and the volume variation simply obtained by $\left(\varepsilon_{11}+\varepsilon_{22}+\varepsilon_{33}\right)$. This technique is very interesting and well adapted for polymers under static loading. As the true strain is calculated during the tensile test in real time, the speed of the tensile grips is controlled throughout the test to keep a constant strain rate which will determine the true stress-strain curves. Nevertheless, this technique could not be used for higher strain rates, such as in crash simulations, due to the limitation of the real time controlling.

Recently, Parsons et al. [11] presents an experimental investigation of the large strain tensile behaviour of polycarbonate using digital image correlation. The true stress-strain relation is obtained by direct measurement of the displacement field and by calculation of an average stress over the specimen section. The local strain rates are not important enough (less than $0.05 \mathrm{~s}^{-1}$ ) to change the true global stress-strain relation and the experimental data is consequently validated under these conditions. 
2 SEE method (sigma, epsilon, epsilon dot) for determination of material behaviour laws

Classical experimental frameworks used to observe and identify material behaviour for dynamic applications suffer from two main weaknesses:

- the dynamic tensile machines (dynamic actuators, Hopkinson bars, ...) cannot perform tests at constant strain rate. The behaviour laws of strain sensitive materials deduced are therefore determined for mean plastic strain rate.

- Classical measurement techniques (strain gauges, extensometers ...) cannot measure non homogeneous and/or out-plane displacement fields occurring in the necking zone.

Numerical predictions of global variables such as forces and displacements are not affected by these approximations. However, the local variables, such as stress and strain fields, are inaccurately computed for sensitive strain rate materials and/or materials with early presence of necking. Consequently, this will lead to an inability to handle damage and fracture phenomena accurately.

An original experimental framework has been developed to try to overcome the previous lack of experimental displacement measurement by using digital image correlation technique [712] on upsetting tensile tests of plate specimens. The idea is to measure throughout the test the evolution of the local total strain, local total strain rate and local uniaxial stress in different areas of a tensile specimen without controlling the speed of the machine. Some hypothesis must then be made in order to exploit these results.

First of all, the digital image correlation measures the displacement field $\overline{\mathrm{u}}$ occurring on the surface of the specimen between two pictures, by studying the natural observed texture of the material or by using the artificial one obtained by painting the top surface of the specimen with black and white colours in order to obtain different grey scale levels (Fig. 2). 
The local displacement between a reference picture of the Zone Of Interest (ZOIref) and a deformed one (ZOIdef) is defined by

$$
g(R)=f(R+a)
$$

where, $g$ and $f$ are grey level functions corresponding to the deformed and reference pictures, $\overline{\mathrm{x}}$ is the position and $\overline{\mathrm{u}}$ the displacement in the plane $(1,2)$ between the reference picture and the deformed one of the ZOI. It is computed by maximizing the quantity $h(a)$

$$
h(a)=\iint(k) f(x+a) d a
$$

The accuracy of the displacement measurement depends on the quality of the grey scale pattern. The picture is defined by a matrix in which each cell represents a pixel of the video CCD or CMOS digitizers and its value varies from 0 (white colour) to 255 (black colour) in the case of 8 -Bits code. The repetitiveness of the painting application has to be checked to avoid dispersions due to grey scale patterns.

The Green Lagrange in-plane strain tensor $(\varepsilon)$ is deduced from the displacement fields of the ZOI. The heterogeneity of the strain field in the Region Of Interest of the specimen (ROI) during the upsetting tensile test can be managed (Fig. 3). The strain field at the fracture initiation and propagation can be computed if the frame per second of the video enables one to observe the fracture phenomena.

A hypothesis on the material behaviour (incompressibility, transverse isotropy ...) has to be made to calculate the through-thickness strain $\varepsilon_{33}$ in order to deduce the tensile stress $\sigma_{11}$ in each ZOI by using

$$
\sigma_{11}=\frac{f}{\sigma_{b}} g^{2} g^{2}=
$$


in which $\mathrm{f}$ is the force through the ZOI transverse section, $\mathrm{S}_{0}$ is the initial transverse section, $\varepsilon_{22}$ obtained by digital image correlation and $\varepsilon_{33}$ obtained by hypothesis ( $\operatorname{Tr} \varepsilon=0$ incompressibility or $\varepsilon_{33}=\varepsilon_{22}$ transverse isotropy) are the transverse strains.

The current section of the specimen throughout the test is then calculated by the sum of the section of each ZOI along the cross section. It is very similar to the calculation made with the average strain option for the cross section.

To perform such a calculation a hypothesis must be made on the local force $\mathrm{f}$ in the equation (3) applied to each ZOI. Considering an initial rectangular tensile specimen, the total force applied when the tensile test starts can be divided equally in each ZOI over a cross section if each ZOI has the same initial dimension. During the tensile test, this distribution of the total force on each ZOI will stay the same. The dimension of each ZOI according to its location on the specimen, will evolve differently but local initial force distribution will be conserved. To check this hypothesis, a finite element tensile test calculation has been done on a simple example (Fig.4). The local forces were determined by section force in some elements (3 elements out of 8 on the cross section) and each local force on each element calculated by hypothesis of the same distribution as the initial state. The force obtained for three elements was divided by 3 to obtain the local force and the sum of 8 times this local force compared to the global one. No important differences have been observed (Fig. 5). The local stress is then determined with the equation (3) and compared to both the equivalent von Mises stress and the uniaxial stress from the finite element simulation. The error obtained is less than $4 \%$ and leads to conclusion of the validation of the hypothesis which allows the conservation of the stress level over a cross section (Fig. 6).

For strain rate sensitive material, the equivalent total strain rate is calculated by backward finite difference using

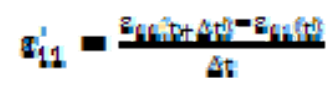


where $\varepsilon_{11}^{*}$ is the total strain rate in the tensile direction and $\Delta$ t time between two pictures.

For each ZOI, the triple point $\left(\sigma_{11}, \sigma_{11}, \dot{\varepsilon}_{11}\right)$ is plotted in the space of stress, total strain and total strain rate to form the SEE (Sigma, Epsilon, Epsilon dot) material behaviour surface (Fig. 7a). The material behaviour law is deduced by cutting the material behaviour surface at the desired total strain rate (Fig. 7b).

The results obtained by this cutting are a set of curves defining the behaviour of the material for a large plastic strain rate range, as well as for a large plastic strain range, particularly after necking.

\section{Application to a semi-cristalline polymer}

The polymer used during this study is a polypropylene charged with around $20 \%$ of talc. The specimens used in this study are cut by water jet from moulded plates. Tests are carried out at room temperature and the evolution of the temperature due to the mechanical deformation is not taken into account. The tensile global mechanical behaviour of this polymer is described by three main stages (Fig.8).

First of all, a quasi linear behaviour in terms of stress-strain evolution is observed which could be strain rate dependent. Secondly, a tension hook during which the necking will occur corresponding to the permanent deformation. This diffuse necking is mainly due to the reorientation of the macromolecule chain under the uniaxial tension effect. This stage is followed by the most important part during which the deformation of the polymer is accompanied by a structural hardening at the end of the process. Finally, a local necking will appear just before failure of the specimen.

This polymer is of course very strain rate dependent and its global behaviour is difficult to describe with a simple analytical model on a large range of plastic strain rates [8-9-10]. 
Consequently, the SEE method presented above is a good tool to determine the real behaviour of this material for a large range of plastic strains and plastic strain rates.

To cover sufficient plastic strain rate values, five tensile speed loadings have been chosen: $5 \mathrm{~mm} / \mathrm{min}, 420 \mathrm{~mm} / \mathrm{min}, 0.01 \mathrm{~m} / \mathrm{s}, 1 \mathrm{~m} / \mathrm{s}$ and $6 \mathrm{~m} / \mathrm{s}$. According to the tensile specimen dimensions (Fig. 9), the mean plastic strain rates will be $0.0027 \mathrm{~s}^{-1}, 0.23 \mathrm{~s}^{-1}, 0.3 \mathrm{~s}^{-1}, 33 \mathrm{~s}^{-1}$ and $200 \mathrm{~s}^{-1}$. The ratio between local strain rates and global strain rates is generally about 2.3.

These tensile tests are performed with a static tensile machine ( 2 first speeds) and a hydraulic jack tensile machine ( 3 last speeds). The $420 \mathrm{~mm} / \mathrm{min}$ and $0.01 \mathrm{~m} / \mathrm{s}$ tests are close in terms of mean strain rate to check the validity of the results when the tests are performed on different tensile machines. The evolution of the force corresponds to the classical behaviour of a polymer with, first of all, an elastic part strain rate dependent, a hook where the polymer chains evolve until their alignment and a flat behaviour corresponding to the tensile resistance of the chains with development of the diffuse necking (Fig.10).

The force increases by around $70 \%$ as the loading speed is multiplied by 5 decades. The strain rate effect is, for this polymer, very important. The elongation at failure also increases with the strain rate and consequently increases the range of the values of the plastic strain and plastic strain rate present on the tensile specimen. The quantity of information on the tensile specimen with the dynamic tests is therefore higher than that with a static test. The comparison of the results obtained by the different tensile machines clearly illustrates that all areas are covered. Even if the ranking is not respected between the two closest speeds, the results are very close and acceptable regarding the dispersion which can be observed. The correlation image technique is applied to the tensile specimen by using static and speed cameras. The pattern is specifically studied for this polymer to avoid any problems due to the 
change of texture as well as to avoid the loss of the optical properties by cracking or delaminating during deformation (Fig.11). A high temperature paint is used for this purpose and the correlation error given by digital image correlation software is never higher than two grey levels (for 256 grey levels). Moreover, no sudden change in the texture is observed during tests which leads to the conclusion that no cracks are appeared on the specimen surface. The uncertainty level on the displacement measurement is determined using a rigid body displacement and the uncertainty observed is about $1,6 \times 10^{-4} \mathrm{~mm}$. The global force and the displacement in each ZOI are recorded for the entire test.

The total strain and total strain rate are determined in each ZOI by calculation based on a Green Lagrange formulation. Finally, the true stress is calculated by means of the equation (3) with the transverse isotropy hypothesis $\varepsilon_{22}=\varepsilon_{33}$. To check this hypothesis, a volume has been defined on a specimen and its longitudinal, transversal and thickness total strain evolutions recorded with two cameras during a tensile test by means of the digital image correlation (Fig. 12).

The evolution of the transverse strains, $\varepsilon_{22}$ and $\varepsilon_{33}$,obtained experimentally are very similar (Fig. 12a) and if $\varepsilon_{33}$ is obtained by using the incompressible hypothesis then the result of the evolution of $\varepsilon_{33}$ is very different from the experimental one (Fig. 12b). For this polymer, the transverse isotropy hypothesis is validated and the true stresses calculated using the corresponding equation. The information for each ZOI about the evolution of total strain, true stress and strain rate are then reported in a three dimensional graph (Fig. 13).

The information from one test is rich and covers only a part of the strain rate range for the surface of the behaviour of the material. To complete the surface all the tensile tests at 
different speed loadings are exploited using the same technique. Finally, the SEE surface is obtained for a range of $10^{-2} \mathrm{~s}^{-1}$ to $30 \mathrm{~s}^{-1}$ for this polypropylene (Fig. 13).

The SEE surface obtained is limited by the results determined during all tensile tests. Of course, some information about higher strain rates is known but only for some values of total strains. In consequence, this information is not presented on the SEE surface. To complete the SEE surface for higher strain rates some tests at higher speeds are necessary and will be performed in the near future with Hopkinson bars. This new technique has a lot of advantages, especially in terms of potential exploitation, to determine the behaviour law of material on large plastic strains and plastic strain rates. First of all, the SEE surface can be easily cut by plane areas defined by a constant total strain rate value. A set of true strain - true stress curves are then determined at constant strain rates and can be used to define analytical mathematical models of behaviour law for the material studied (Fig. 14).

Moreover, these curves are defined for a large plastic strain range and certainly after the occurrence of necking which is obviously a great advantage for the model definition when compared to the classical identification method.

A comparison with the technique developed by G'sell is carried out to validate the SEE method. First of all, some tensile tests using the video traction $^{\mathrm{TM}}$ technique are performed at the controlled strain rate of $5.10^{-3} \mathrm{~s}^{-1}$ and $5.10^{-4} \mathrm{~s}^{-1}$. As explained by G'sell, the results are obtained by measuring the displacements between spots (Fig. 1) and calculating the strain and corresponding stress (Fig.14).

The results obtained confirm the quality of the SEE method by respecting the ranking of the curves and the level of stress and strain, they also complete the SEE surface for the quasi 
static loadings. Some minor differences appear however between the video $\operatorname{traction}^{\mathrm{TM}}$ and the SEE method which could be due to the fact that the tests for the two methods are done with different specimens and also with different tensile machines. Nevertheless, the difference between $5.10^{-3} \mathrm{~s}^{-1}$ and $10^{-2} \mathrm{~s}^{-1}$ is very small and could be due to the experimental dispersion. These two techniques are complementary and cover a better range of total strain rates.

The SEE method is therefore validated and gives the opportunity to use the complete heterogeneous displacement field on a tensile specimen to determine accurate behaviour laws for strain rate dependent materials.

\section{Conclusions}

In this paper a new methodology to determine behaviour laws for strain rate dependant materials for a large range of plastic strains and plastic strain rates is proposed. This methodology uses the heterogeneity of the displacement field observed on the surface of a tensile specimen. This displacement field is measured by a correlation image technique on different zones on the specimen and the total strains associated are calculated by a Green Lagrange formulation. The corresponding strain rates are obtained from the previous calculations and finally the true stresses are obtained by using the incompressible or transverse isotropic hypothesis. All this information is transferred to a behaviour surface called the SEE surface which represents the behaviour of the material in the space of stress, true strain and strain rate. A set of true stress-true strain laws at constant strain rates are then obtained by cutting the SEE surface by the plane area defined by constant strain rates. Behaviour models could then be identified by means of this set of curves.

This new technique is applied to a polypropylene polymer. This material is strain rate dependent and has an early diffuse necking which introduces a heterogeneous plastic strain field on its surface during a tensile test. Different tensile speed loadings are applied to cover a 
large strain rate range. The SEE surface is built and cut to define a set of behaviour laws which are compared to behaviour laws obtained by low speed tests based on the video traction $^{\mathrm{TM}}$ technique. The quality of the results obtained and the accuracy of the measurements highlight the great interest of the SEE method.

\section{Acknowledgments}

The present research work has been supported by International Campus on Safety and Intermodality in Transportation, the Région Nord Pas de Calais, the European Community, the Délégation Régionale à la Recherche et à la Technologie, the Ministère de l'Enseignement Supérieur et de la Recherche, and the Centre National de la Recherche Scientifique: the authors gratefully acknowledge the support of these institutions.

\section{References}

1. Bridgman P.W. Studies in large plastic flow and fracture. Mc Graw-Hill 1952, New York. 2. Ling Y. Uniaxial true stress-strain after necking. AMP Journal of Technology 1996; 5:3748.

3. Lauro F., Bennani B., Oudin, J. Identification of the damage parameters for anisotropic materials by inverse technique: application to an aluminium. Journal of Material Processing Technology 2001; 118:472-477.

4. Zhang Z.L., Hauge M., Odegard J., Thaulow C. Determining material true stress-strain curve from tensile specimens with rectangular cross-section. International Journal of Solids and Structures 1999; 36:3497-3516.

5. Zhang Z.L., Odegard J., Sovik O.P. Determining true stress-strain curve for isotropic and anisotropic materials with rectangular tensile bars: method and verifications. Computational Materials Sciences 2001; 20:77-85. 
6. G'sell C., Hiver J.M., Dahoun A. Experimental characterisation of deformation damage in solid polymers under tension, and its interrelation with necking. International Journal of Solids and Structures 2002; 39:3857-3872.

7. Hild, F., Raka, B., Baudequin, M., Roux, S., Cantelaube, F. Multiscale displacement field measurements of compressed mineral-wool samples by digital image correlation. Applied Optics 2002; 41:6815-6828.

8. Lauro F., Oudin J. Static and dynamic behaviour of a polypropylene for bumpers. International Journal of Crashworthiness, 2003;8:553-558.

9. Spingler G., Drazetic P., Markiewicz E. Dynamic characterization of polymers to improve numerical simulations for passive safety. International Journal of Crashworthiness 2005; 10:87-101.

10. Tillier Y., Massoni E., Billon N. Inverse method for the characterisation of mechanical behavior of polymers under biaxial high velocity loading. Computational Mechanics 1998; Barcelona.

11. Parsons E., Boyce M.C., Parks D.M. An experimental investigation of the large strain tensile behavior of neat and rubber-toughened polycarbonate. Polymer 2004;45:2665-2684

12. Chevalier L., Marco Y. Tools for multiaxial validation of behavior laws chosen for modelling hyper-elasticity of rubber-like materials, Polymer Engineering Science 2002;

42:280-298. 


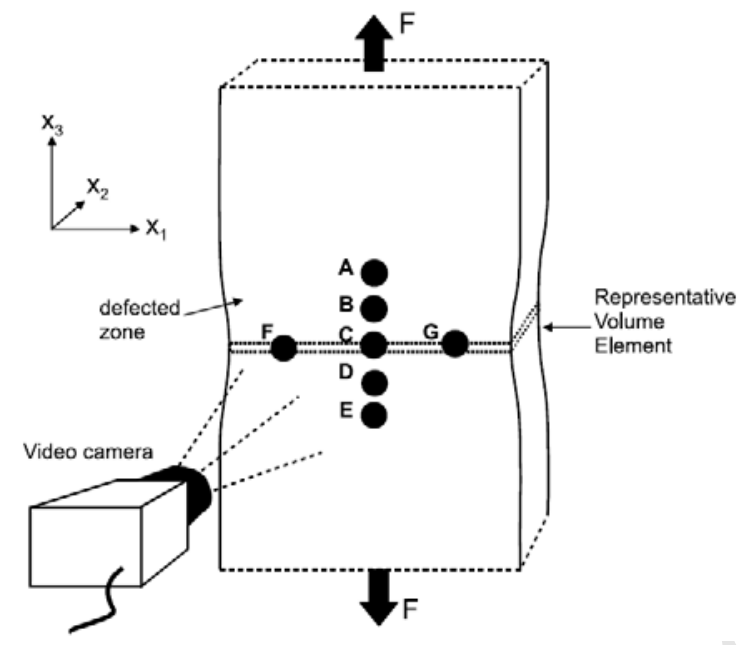

Figure 1. Configuration of the seven markers in the video-controlled tensile testing system [6].

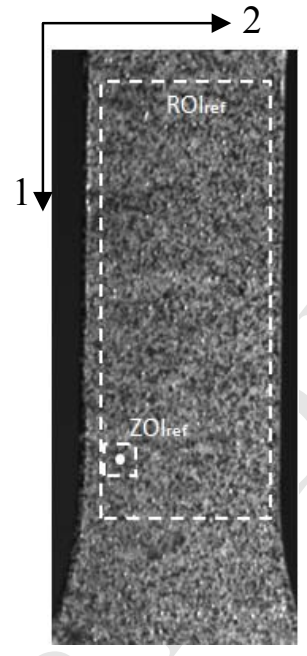

(a)

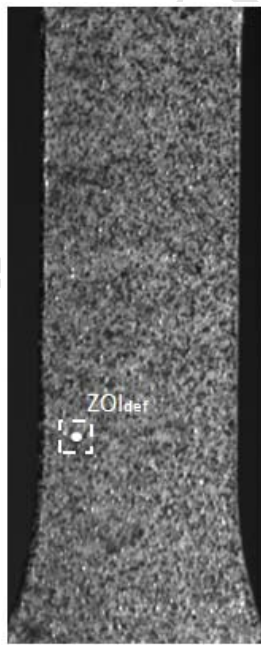

(b)

Figure 2. ROI and ZOI on a flat specimen for (a) the reference picture and (b) the deformed one. 


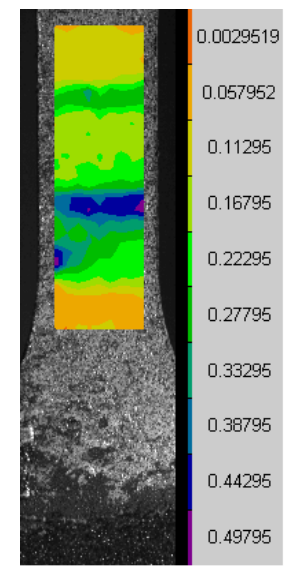

Figure 3. Tensile total strain field in an upsetting tensile test of flat specimen. 

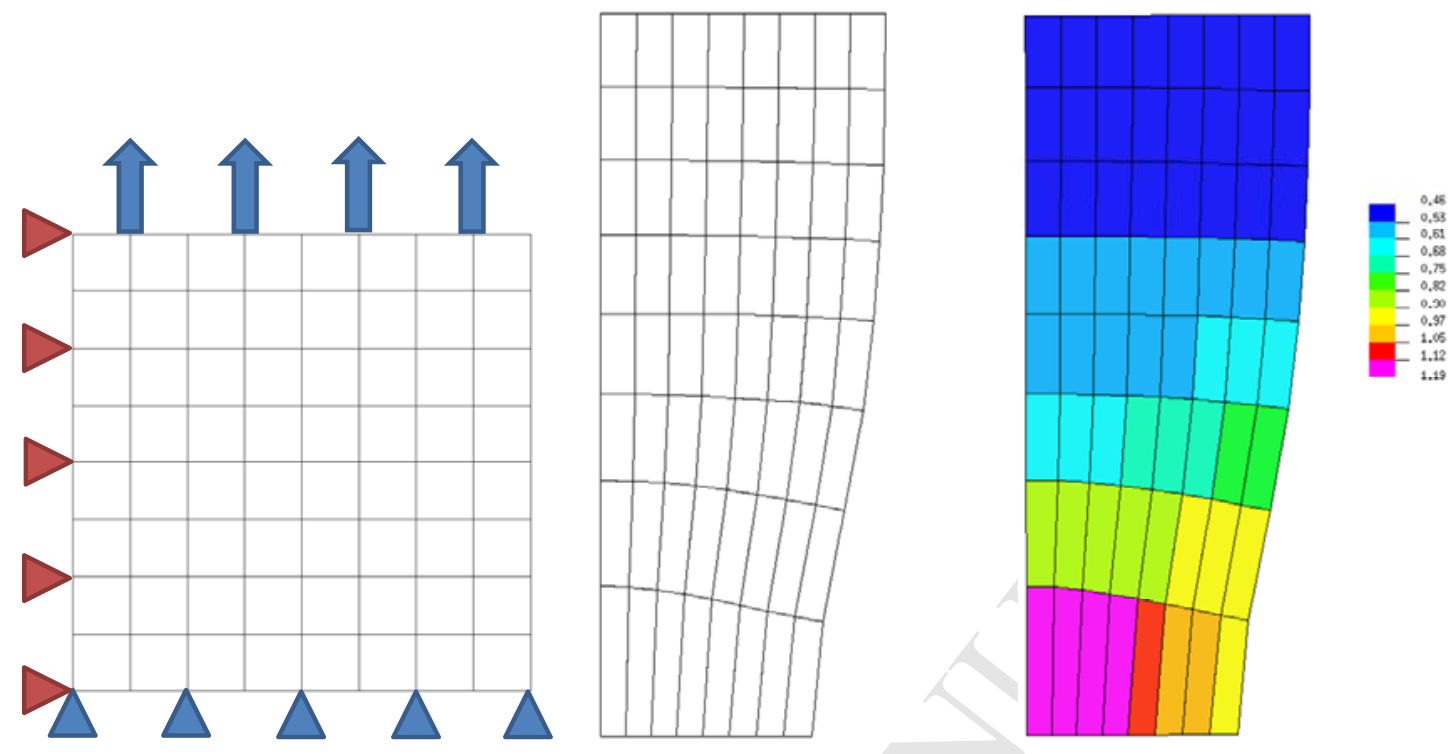

Figure 4. Initial and deformed mesh with plastic strain information

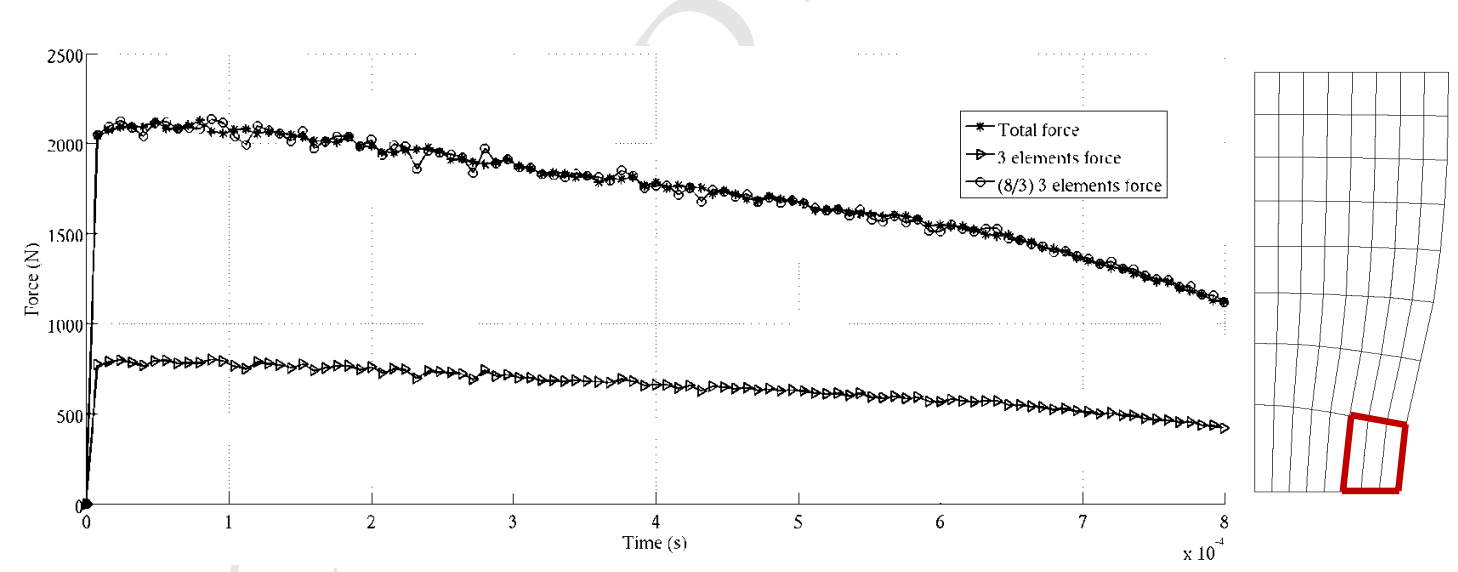

Figure 5. Comparison of the total force and the sum of the 8 local forces based on the measurement on 3 elements over a cross section. 


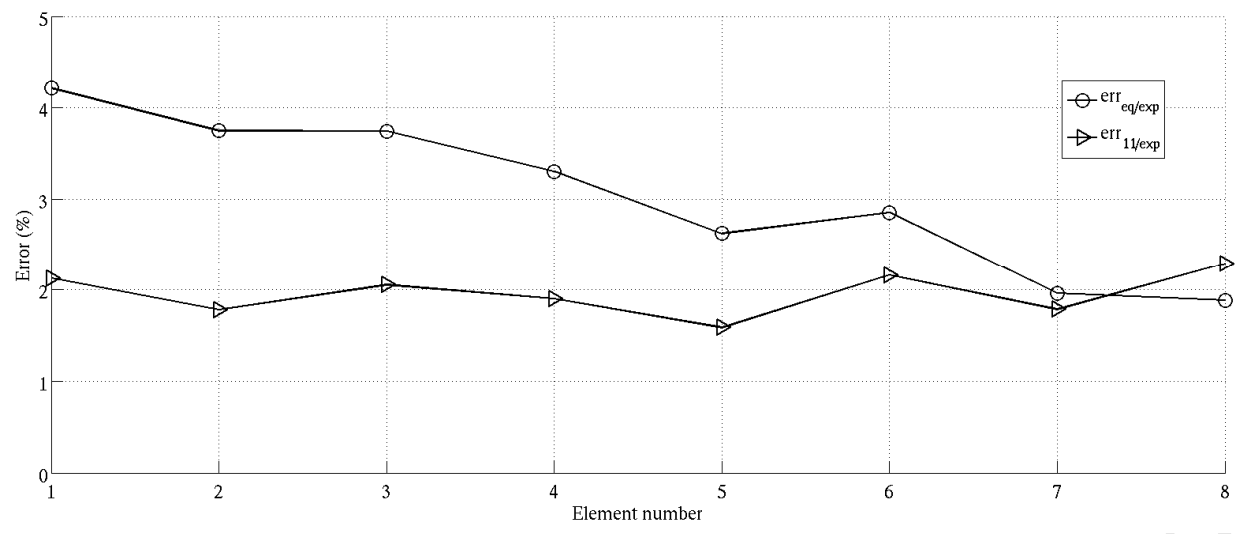

Figure 6. Error obtained with local stress calculation with the SEE method and the finite element ones with von Mises equivalent stress eq/exp and uniaxial stress 11/exp in each element over the cross section.

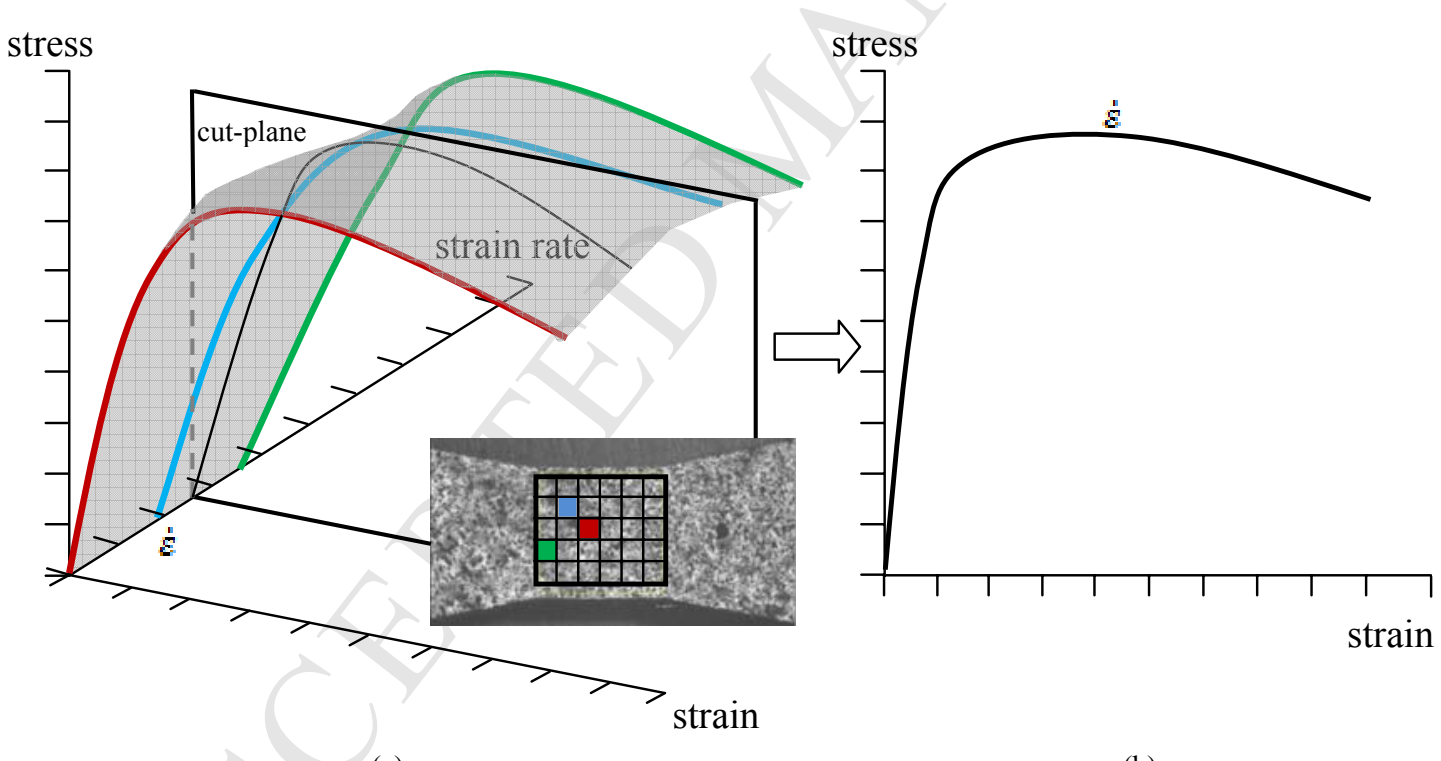

(a)

(b)

Figure 7. (a) SEE surface construction from ZOIs and (b) material behaviour law at desired constant strain rate deduced from SEE surface. 


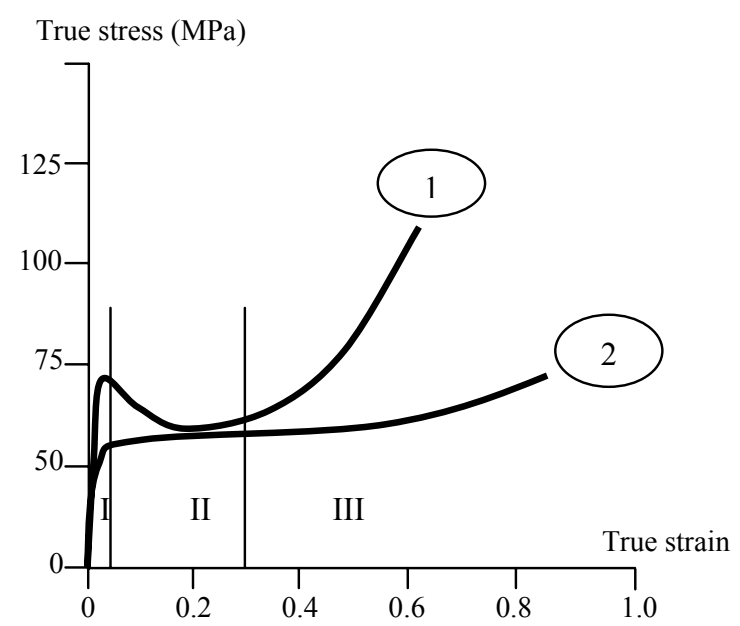

Figure 8 . Behaviour of polymers.

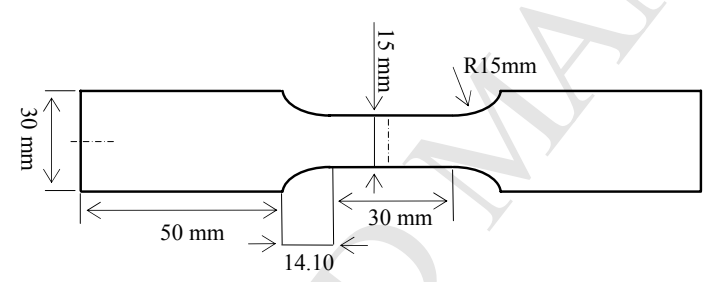

Figure 9. Tensile specimen dimension (thickness of $3 \mathrm{~mm}$ ). 


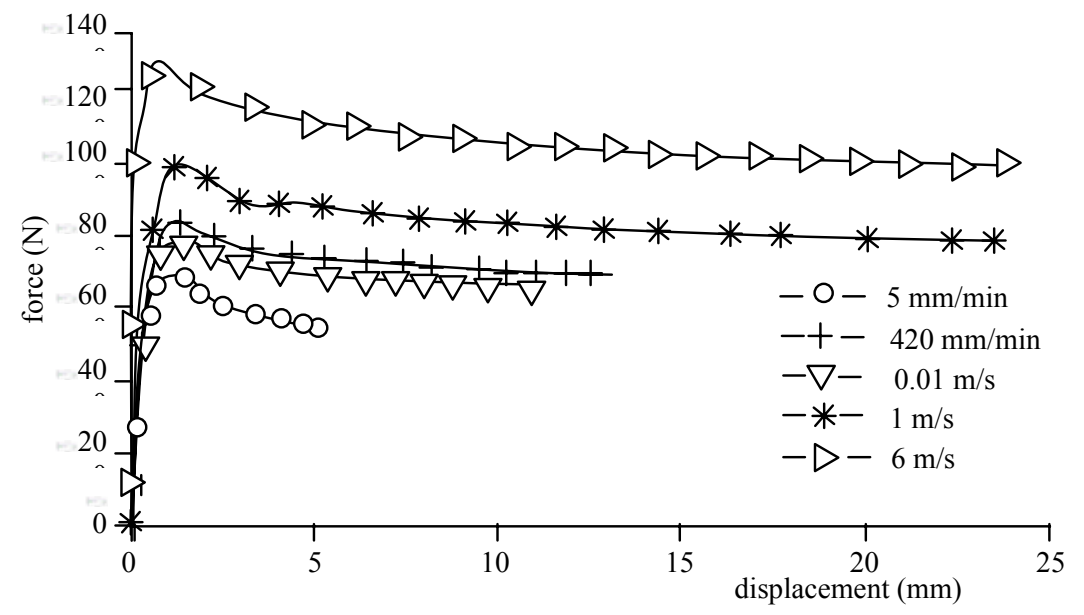

Figure 10. Force displacement curves for different actuator velocities.

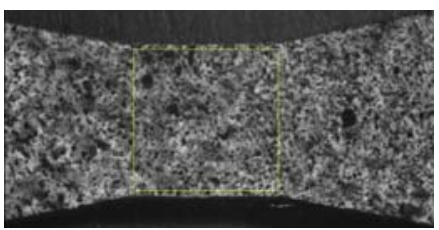

(a)

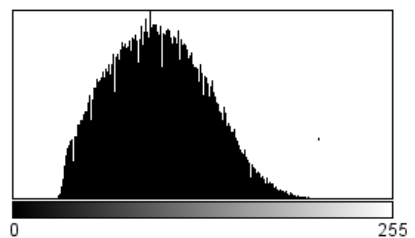

(b)

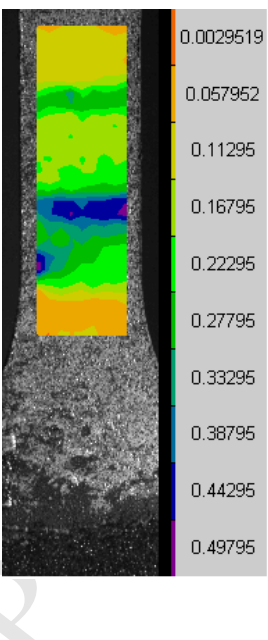

(c)

Figure 11. (a) Grey scale pattern, (b) quality test of grey scale pattern and (c) total strain field on the tensile specimen. 


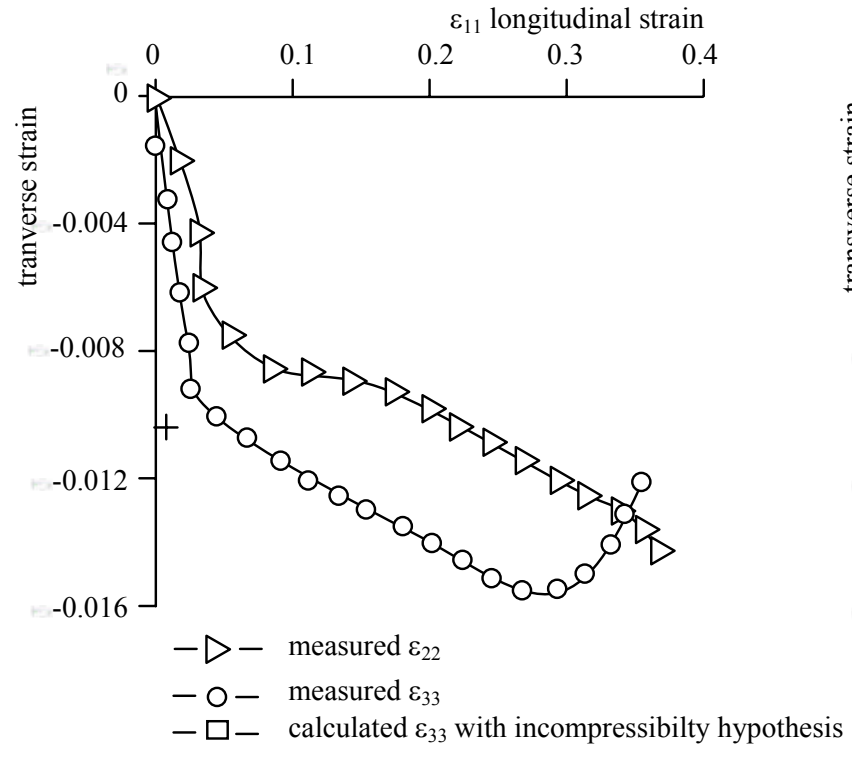

(a)

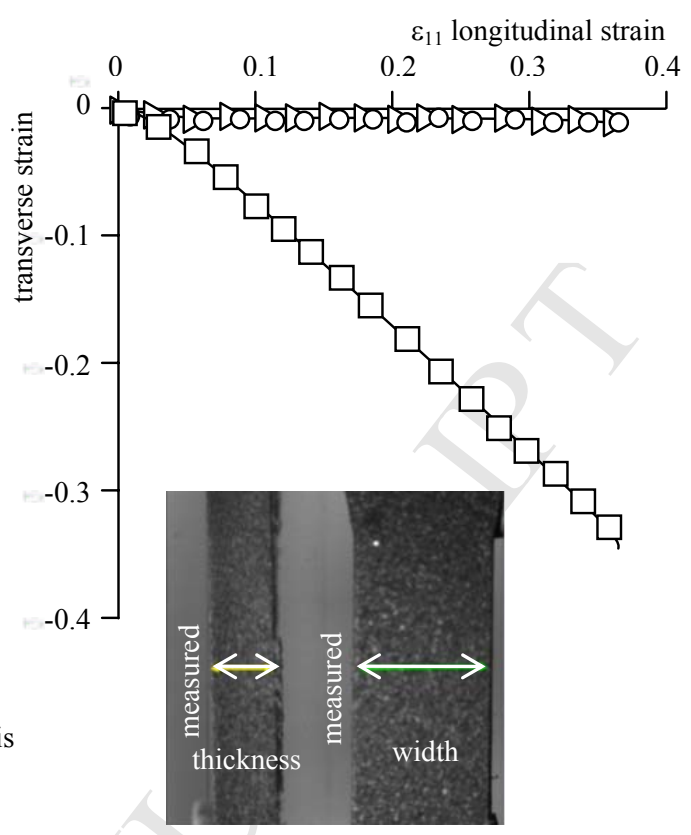

(b)

Figure 12. (a) Evolution of measured (with two cameras) transverse strain versus longitudinal strain and (b) comparison between in width measured strain and calculated strain with incompressibility hypothesis. 


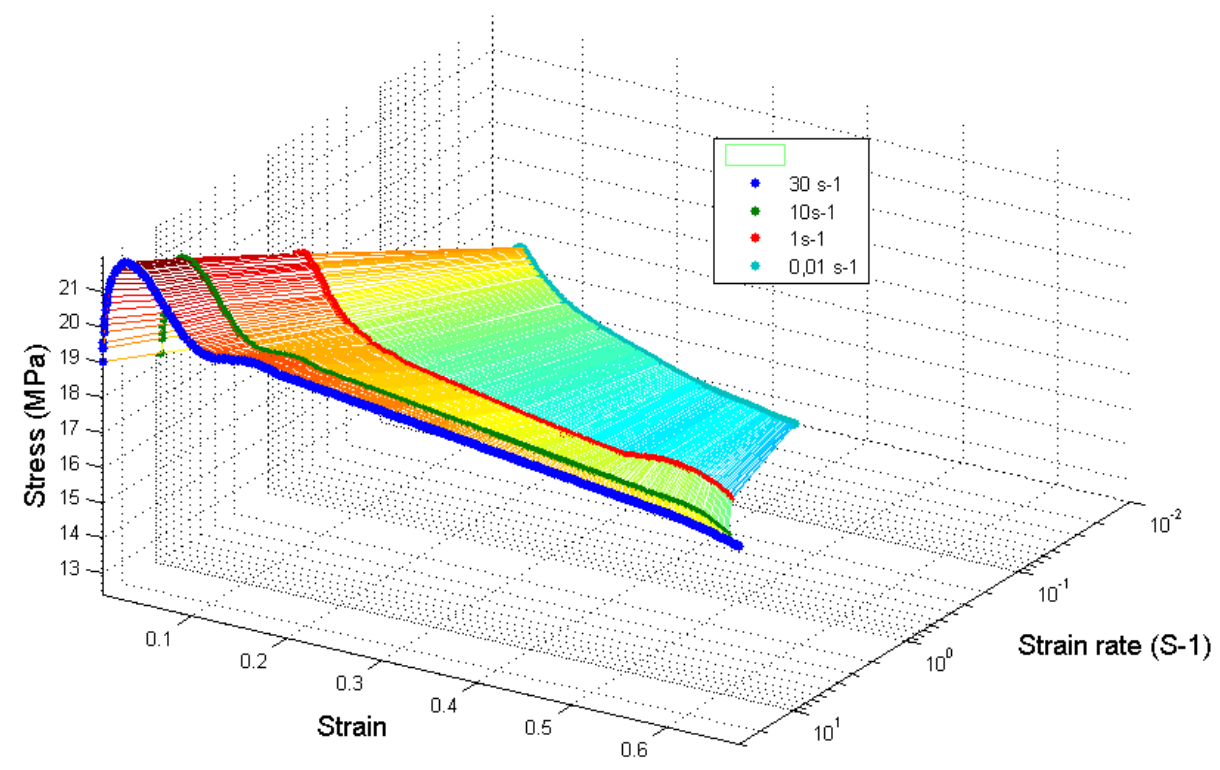

Figure 13. The SEE் surface.

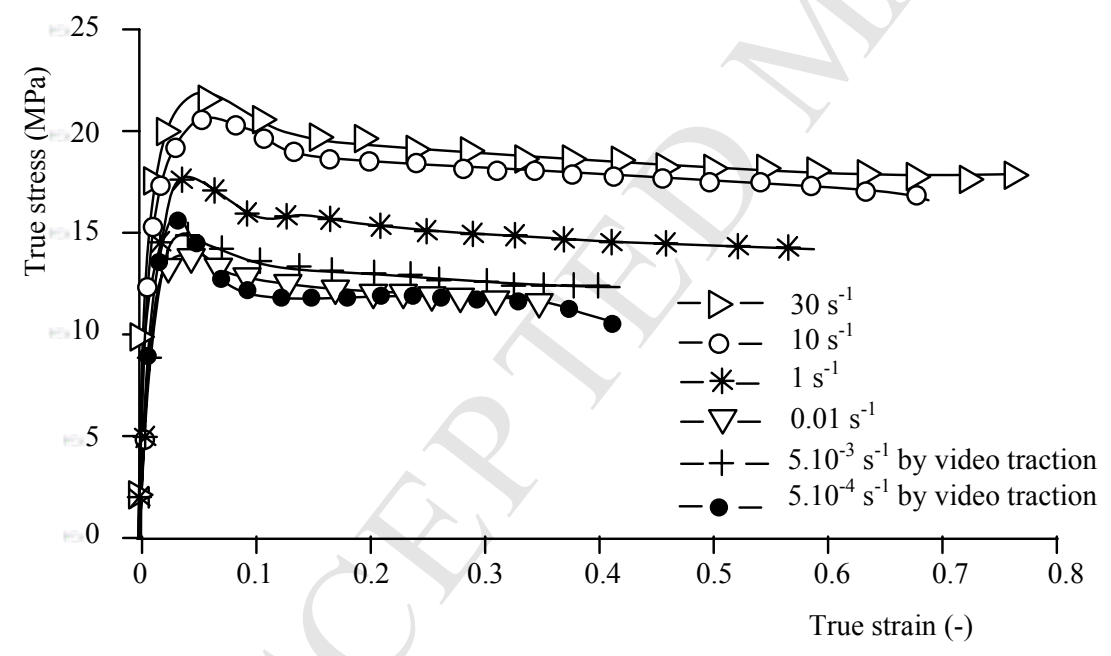

Figure 14. True stress- true strain curves for different strain rates. 